\title{
Editorial
}

\section{Decisiones y elecciones: El diseño de la investigación cualitativa}

\section{Decisions and choices: The design of qualitative research}

\section{Decisões e escolhas que: $\mathrm{O}$ desenho de pesquisa qualitativa}

Carmen de la Cuesta Benjumea

Profesora titular Departamento de Psicología de la Salud. Universidad de Alicante.

Cómo citar este relato en edición digital: de la Cuesta Benjumea, C. (2015). Decisiones y elecciones: El diseño de la investigación cualitativa. Cultura de los Cuidados (Edición digital) 19, 43. Disponible en: <http://dx.doi.org/10.14198/cuid.2015.43.01>

Correspondencia: Departamento de Psicología de la Salud. Universidad de Alicante. CP 03080, Alicante.

Correo electronico: ccuesta@ua.es

Recibido: Autora invitada

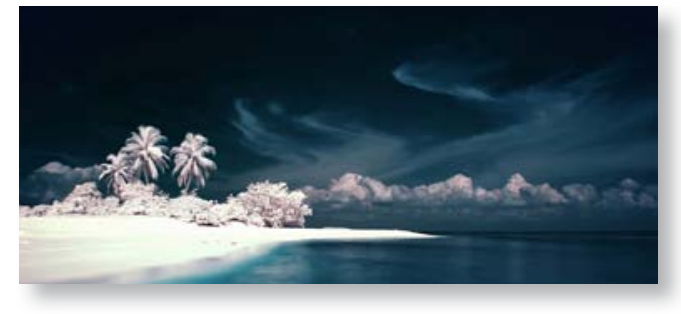

\section{ABSTRACT}

In this editorial the author reflects on the different forms of decisions and choices about the design in qualitative research.

Keywords: Qualitative Research; nursing.

\section{RESUMO}

Neste editorial, o autor reflecte sobre as diferentes formas de decisões e escolhas sobre o design na pesquisa qualitativa.

Palavras chave: Pesquisa qualitativa; enfermagem.

\section{RESUMEN}

En esta editorial la autora reflexiona sobre las diferentes formas de decidir y elegir acerca del diseño en investigación cualitativa.

Palabras clave: Investigación Cualitativa; enfermería.
La ejecución de un estudio de investigación implica tomar una serie de decisiones y hacer elecciones. La primera, es optar entre llevar a cabo un estudio cualitativo o cuantitativo, superado este escollo, que no es poco, quien investiga se ve enfrentado en elegir una estrategia, enfoque o diseño. Ante él o ella se abre un abanico de múltiples, desconocidas y a veces, extrañas posibilidades.

¿Cómo poder elegir si de ante mano se ignora la naturaleza de los diversos métodos? ¿Cómo saber si se será capaz de llevarlos a cabo? En este punto se suele buscar consejo e información, pero la verdad es que en los inicios se va a algo tientas y con la sensación de quizás, haberse equivocado. La información parece insuficiente y en realidad lo es, pues hasta que los métodos no se experimentan no se les conoce verdaderamente. Entrar a diseñar un proyecto con esta incertidumbre, que la llevamos hasta el trabajo de campo, no es malo mas bien es ventajoso, aunque reconozco que incomodo. La sensación de no saberlo todo, sitúa a quien investiga próximo a las vidas de los participantes. La fragilidad y 
vulnerabilidad que se siente al plantear un estudio y al llevarlo a cabo, abre a la experiencia del otro y a escuchar lo que tiene que decir. $\mathrm{Al}$ mundo hay que salir aunque sea cojeando, decía Foucault cuando sus estudiantes le pedían certidumbres, y creo que en la investigación cualitativa, un nuevo mundo para muchos, se sale de esta manera. Cojeando, ipero no empujado! Es decir, con cierto saber sobre la elección hecha.

Dado por sentado que se ha optado por estudiar el mundo de la manera cualitativa, la cuestión ahora es, cómo entrar teóricamente en él. En la investigación en salud confluyen los métodos cualitativos que provienen de diversas disciplinas, cada una con su lenguaje, sus particularidades pero también sus puntos en común, el campo de la salud es en verdad multidisciplinar. Así que, lo primero para hacer una buena elección, es poder entender el lenguaje del método y distinguir equivalencias y diferencias. Por ejemplo, lo que en la etnografía se denomina punto de vista "emic" en la teoría fundamentada se llama la "experiencia del interior" y en la fenomenología "experiencia vivida”. Estos términos son equivalentes, pero no iguales, las bases disciplinares de cada uno de ellos va a dar el matiz particular. Además de hacerse con un lenguaje, es necesario familiarizarse con el marco teórico que sustenta una metodología dada. Esto no significa que quien investiga se haga sociólogo, filósofo o teórico crítico. Significa, que conozca y luego comparta, los supuestos teóricos que subyacen en el método. Esto ayudará a plantear el problema a investigar y en el diseño del estudio, a que la elección hecha tome cuerpo.

Es común que al principio todo parezca igual y a la vez distinto, que la confusión sea grande y que quien se acerca por primera vez a los métodos cualitativos, se sienta algo abrumado o abrumada. Aquí la tentación suele ser tomar un poco de cada método, pues la verdad, es que todos parecen atractivos; la elección no suele ser fácil. Se está poco acostumbrado a tener que elegir entre diversos métodos, lo tradicional en el área de la salud ha sido el monoteísmo metodológico, es decir la creencia de que para investigar solo hay un método verdadero. Mezclar entre métodos no es aconsejable, sobretodo a quienes inician la andadura. Lo que la práctica muestra, es que con el tiempo los investigadores cualitativos tienen preferencias e inclinaciones que hace que se especialicen en un método o estrategia cualitativa de investigación. Se especializan, pero no se quedan ahí sino que, con la práctica, lo desarrollan. Los métodos se crean de nuevo en cada proyecto, por investigadores que llevan su trabajo a un estándar, afirma Sandelowski (2008).

En los inicios, la decisión sobre qué camino metodológico tomar es producto de un dialogo que quien va a investigar tiene consigo mismo o consigo misma. En este dialogo considera sus gustos e inclinaciones, su vocación, biografía y cómo no, la persona que va orientar el trabajo. Pero no todo esta claro ni es racional, a la intuición se la debe también escuchar. Una vez elegido el método cualitativo, el compromiso metodológico es flexible, nada es irrevocable. Es en la práctica donde se dirimen estas cuestiones. Así que la decisión es provisional, permite salir cojeando y avanzar.

Resuelta la cuestión del enfoque metodológico, en cada proyecto y estudio de investigación quien investiga se enfrentara a un sin numero de decisiones. El primer acercamiento a la bibliografía le irá orientando el camino, pasará de desarrollar el problema a investigar 
a plantear la estrategia para hacerlo. Aquí, las decisiones de orden metodológico que tome, son bastantes prácticas además de éticas. Tendrá que valorar honestamente si tal como está planteando el estudio lo puede llevar a cabo y si lo debe llevar a cabo.

Una vez en el campo, la estrategia se pone a prueba así como la capacidad de quien investiga para resolver los problemas que surjan. A los diseños los limita las restricciones que hay en la practica (Denzin y Lincoln 1994), pero se desconocen de antemano. En verdad, el diseño cualitativo consiste en tomar decisiones; quien investiga no actúa por diseño sino que al actuar, es decir al ejercer como investigador o investigadora, diseña su estudio. La consulta bibliográfica, la reflexividad, la intuición y los diálogos con orientadores y pares ayudaran a que tome las mejores decisiones. Pero las elecciones no finalizan aquí, en el análisis se enfrenta, primero, a decidir lo que será dato para su estudio de investigación y luego qué asuntos perseguir. Una vez más, aquí afronta la cuestión de que no puede analizarlo todo y los ecos positivistas de lo exhaustivo, resonarán en su interior. Tendrá que elegir y confiar en que su familiaridad con el tema en estudio y lo que aprendió durante el trabajo de campo, le indicarán el camino. También podrá pensar que lo que descarta lo puede reservar para otro estudio (Charmaz 2014).

Cómo comunicar lo aprendido durante el estudio, es la ultima elección que hace y aquí no encuentro mejor metáfora que la de pensar en un pintor que, ante un paisaje, decide donde mejor situar su caballete. Este es un proceso de visualizar la estructura del informe hasta dar con aquella que se deja escribir. A medida que desarrolla su escrito quien investiga decide qué decir, donde mejor decirlo y qué recursos literarios usar; de esta manera, diseña su escrito para hacer justicia a las vidas de los participantes del estudio.

Investigar cualitativamente no es seguir a ciegas prescripciones metodológicas ni aplicar recetas; implica tomar decisiones algunas informadas, otras intuitivas y otras sugeridas, es en este proceso donde el estudio toma una forma particular, única y específica que reflejará el self de quien investiga. La incertidumbre acompaña todo el proceso y esta es, precisamente, una condición para que prospere el trabajo cualitativo de investigación.

\section{REFERENCIAS}

- Charmaz, K. (2014). Constructing Grounded Theroy. Los Angeles: Sage.

- Denzin, K. y Linclon, YS (1994). Introduction: Entering the Field of Qualitative Research. En: K. Denzin y Y:S. Lincoln (Eds.), Handbook of Qualitative Research, (pp 1-17). California: Sage, Thousand Oaks.

- Sandelowski, M. (2008). Foreword. En: S. Thorne (Ed.), Interpretative description, (pp. 11-14). Ca: The Left Coast Press. 